\title{
Full Mouth Rehabilitation of a Patient having Limited Interarch Space with Mandibular Implant Retained Fixed Adoro Fused to Metal Fp-1 Prosthesis and Maxillary Acrylic Removable Conventional Complete Denture
}

Ashish R Jain, Padma Ariga

\begin{abstract}
Background: According to previous studies, persons wearing implant-retained prostheses may create bite forces comparable to those possessing natural dentition and it has been suggested that the risk for combination syndrome increases in persons wearing mandibular implant-retained prostheses opposed to maxillary complete dentures.
\end{abstract}

Aim: This article presents the fabrication of a maxillary conventional complete denture opposing a mandibular implant retained fixed prosthesis and evaluates the changes in the edentulous maxilla and prostheses over a period of 2 years.

Case description: A comprehensive treatment included a conventional removable complete denture for the upper arch and a six implant supported fixed prosthesis for the lower arch.

Conclusion: This article reports on the fabrication of a maxillary conventional complete denture opposing a mandibular implantretained full fixed prosthesis. Occlusion and articulation were found to be good over a period of 2 years. Retention and stability were found to be good uptill the 18 months review and moderate at the 24 months review.

Clinical significance: To preserve anterior maxillary bone, a balanced occlusal concept has been recommended for implantretained mandibular prostheses opposing a tissue supported conventional maxillary complete denture. In this case, the patient was rehabilitated with a balanced occlusion without anterior tooth contact in maximal intercuspation.

Keywords: Full mouth rehabilitation, Implant retained fixed Fp-1 prosthesis, Complete denture.

How to cite this article: Jain AR, Ariga P. Full Mouth Rehabilitation of a Patient having Limited Interarch Space with Manbibular Implant Retained Fixed Adoro Fused to Metal Fp-1 Prosthesis and Maxillary Acrylic Removable Conventional Complete Denture. Int J Oral Implantol Clin Res 2013;4(3):112-117.

Source of support: Nil

Conflict of interest: None declared

\section{BACKGROUND}

Rehabilitation of the edentulous maxilla with the help of implants continues to be comparatively more challenging than rehabilitation of the edentulous mandible. Though single-stage implant surgery with immediate loading is well established in the mandible, the same should be considered experimental in the maxilla until long-term, evidence-based data and guidelines are established. ${ }^{1}$ Severe resorption is frequently seen in the edentulous anterior maxilla opposed by implant retained or supported dentures in the mandible. This so-called combination syndrome is a result of excessive anterior maxillary loading. ${ }^{2}$

According to previous studies, persons wearing implantretained prostheses may create bite forces comparable to those possessing natural dentition and it has been suggested that the risk for combination syndrome increases in persons wearing mandibular implant-retained prostheses opposed to maxillary complete dentures. ${ }^{3,4}$

\section{AIM}

This article presents the fabrication of a maxillary conventional complete denture opposing a mandibular implant retained fixed prosthesis and evaluates the changes in the edentulous maxilla and prostheses over a period of 2 years.

\section{CASE DESCRIPTION}

A 40-year-old woman reported, complaining of inability to chew, unesthetic appearance of face, difficulty in speech and desired replacement of all missing teeth (Fig. 1). A full mouth radiograph and CT scan was obtained (Figs 2 and 3 ). A comprehensive treatment was planned. This included a conventional removable complete denture for the upper arch and an implant supported fixed prosthesis for the lower arch. The unfavorable sinus anatomy in the posterior maxilla and the patient's unwillingness for bone grafting to facilitate implant placement precluded the placement of implants in the maxillary arch. The treatment plan was discussed with the patient. A two stage implant surgery was scheduled 4 months after extraction.

\section{Stage I: Implant Surgery}

A full thickness mucoperiosteal flap was raised in the mandibular arch from left second molar region to right second molar region. In the right quadrant, implants (Self thread, Touareg ${ }^{\mathrm{TM}}$ NP, Adin dental implant system, Israel) were placed in the molar $(4.2 \times 13 \mathrm{~mm})$, premolar $(4.2 \times 10 \mathrm{~mm})$ 


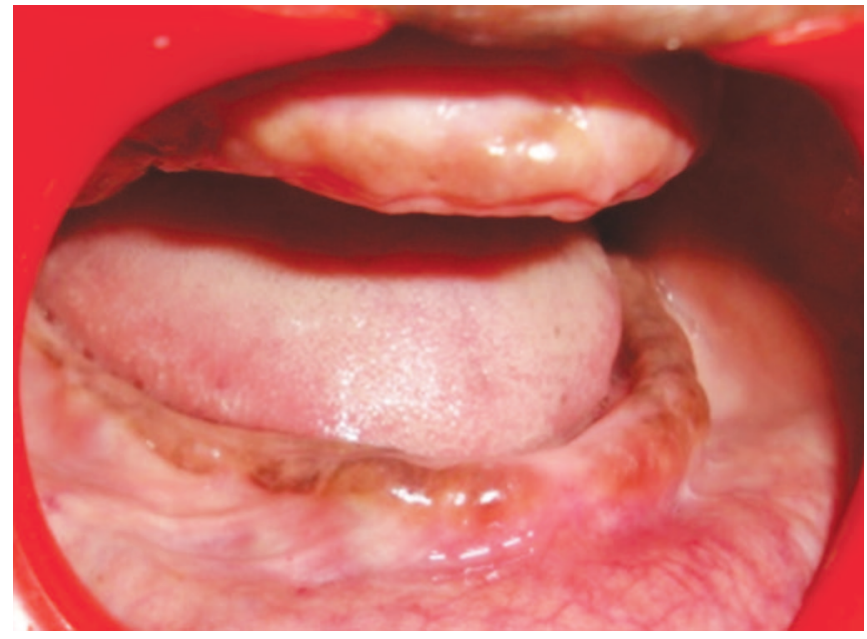

Fig. 1: Preoperative photograph after 4 months of extraction

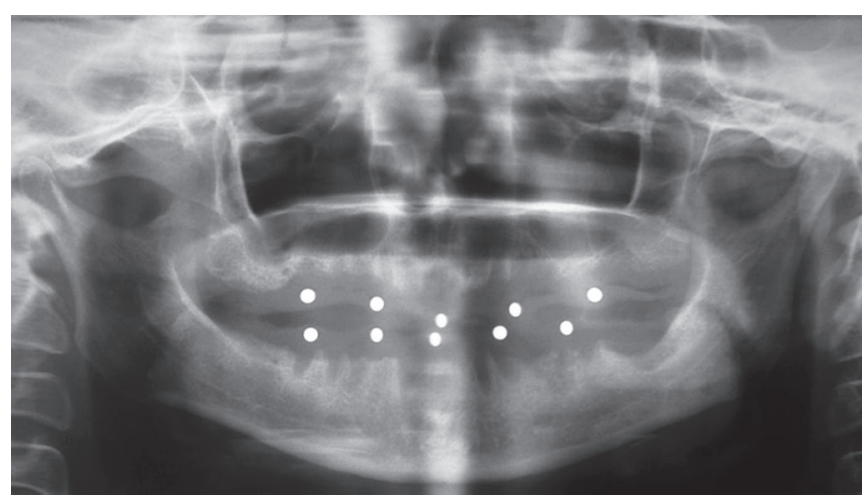

Fig. 2: Postextraction radiograph with radiographic markers in place

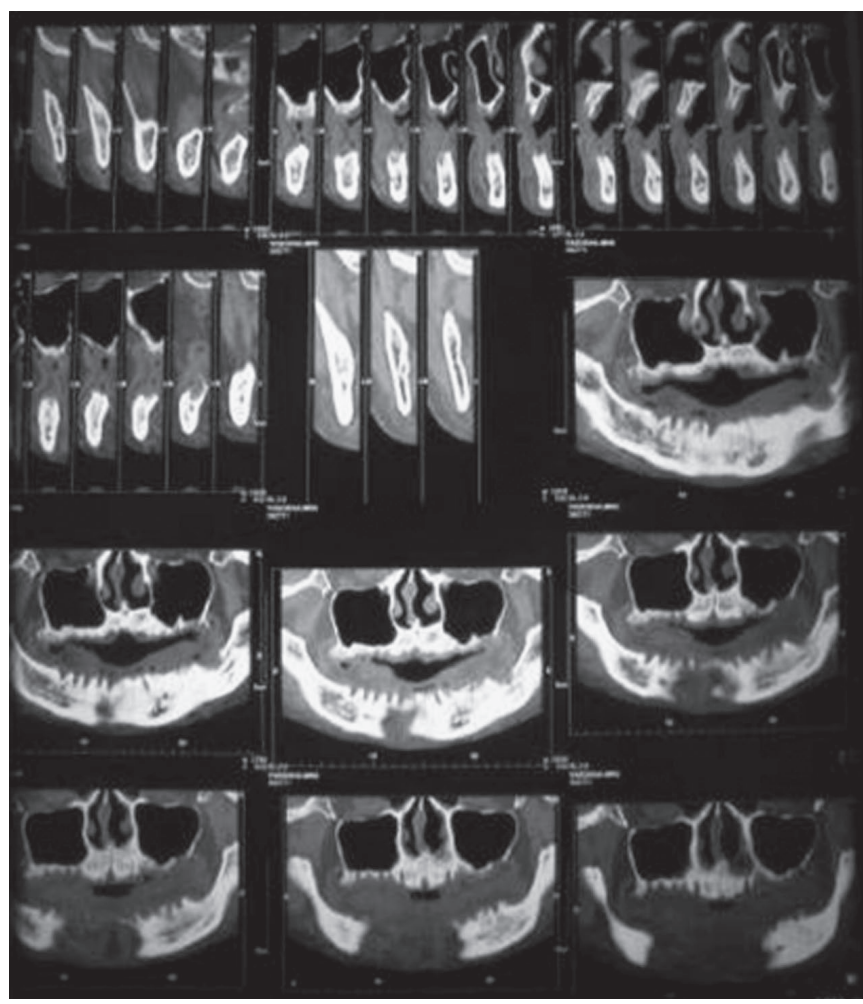

Fig. 3: CT scan to determine the width and height of bone

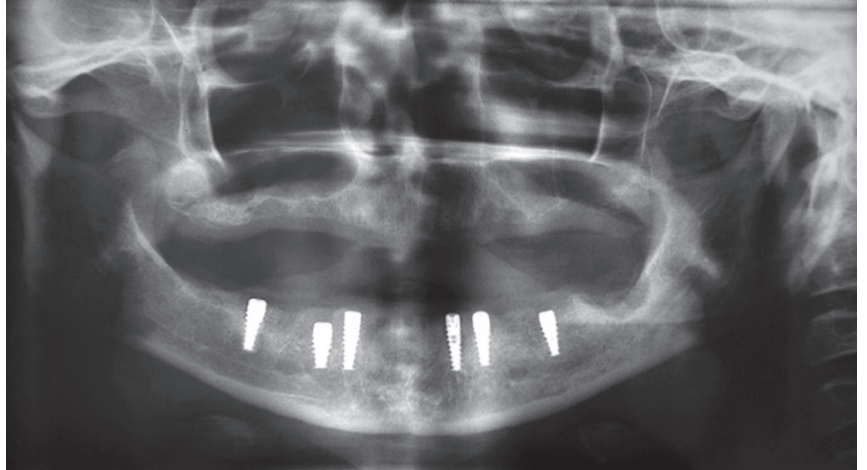

Fig. 4: Radiograph after 6 months of implant placement

and canine $(3.75 \times 13 \mathrm{~mm})$ regions. In the left quadrant, implants were placed in molar $(4.2 \times 10 \mathrm{~mm})$, premolar $(4.2$ $\times 13 \mathrm{~mm})$ and canine $(3.75 \times 13 \mathrm{~mm})$ regions. The implant dimentions were selected with the help of the CT scan. A total of six implants were placed in the mandibular arch. The flap was closed using horizontal interrupted sutures. After 1 week, the sutures were removed and an immediate denture was relined with a permanent soft denture liner (Permasoft, Dentsply, York, PA, USA) and inserted.

\section{Stage II: Implant Surgery}

After a waiting period of 4 months an OPG was obtained to evaluate the bone to implant contact percentage and later stage II surgery was performed under local anesthesis (Fig. 4). Cover screws were exposed and healing abutments were placed and the flap sutured (Figs 5A and B).

\section{Prosthetic Phase}

Maxillary and mandibular arch impressions were made using alginate (Tulip Alginate Impression Material, Cavex, Holland $\mathrm{Bv}$, Haarlem Holland). A conventional special tray was fabricated for the maxillary arch and a custom open tray was fabricated in acrylic resin (Autopolymerizing acrylic resin,

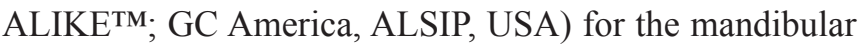
arch. The open tray was verified in the patient's mouth (Fig. 6A). One week later, healing caps were removed from the mandibular implants and impression copings were attached to them. These open tray impressions copings were stabilized with 23 gauge ortho wire and blocked out with acrylic resin (Auto polymerizing acrylic resin, ALIKETM; GC America, ALSIP, USA) (Fig. 6B). The mandibular impression was made with monophase polyvinyl siloxane impression material (Aquasil Lv Ultra, Smart Wetting Impression Material, Dentsply, Detrey Gmbh, Konstanz, Germany) (Fig. 7). Border molding was completed with green stick compound and secondary impression was made using addition silicone impression material (Aquasil Lv Ultra, Smart Wetting Impression Material, Dentsply, Detrey Gmbh, Konstanz, Germany) for the maxillary arch (Fig. 7). 


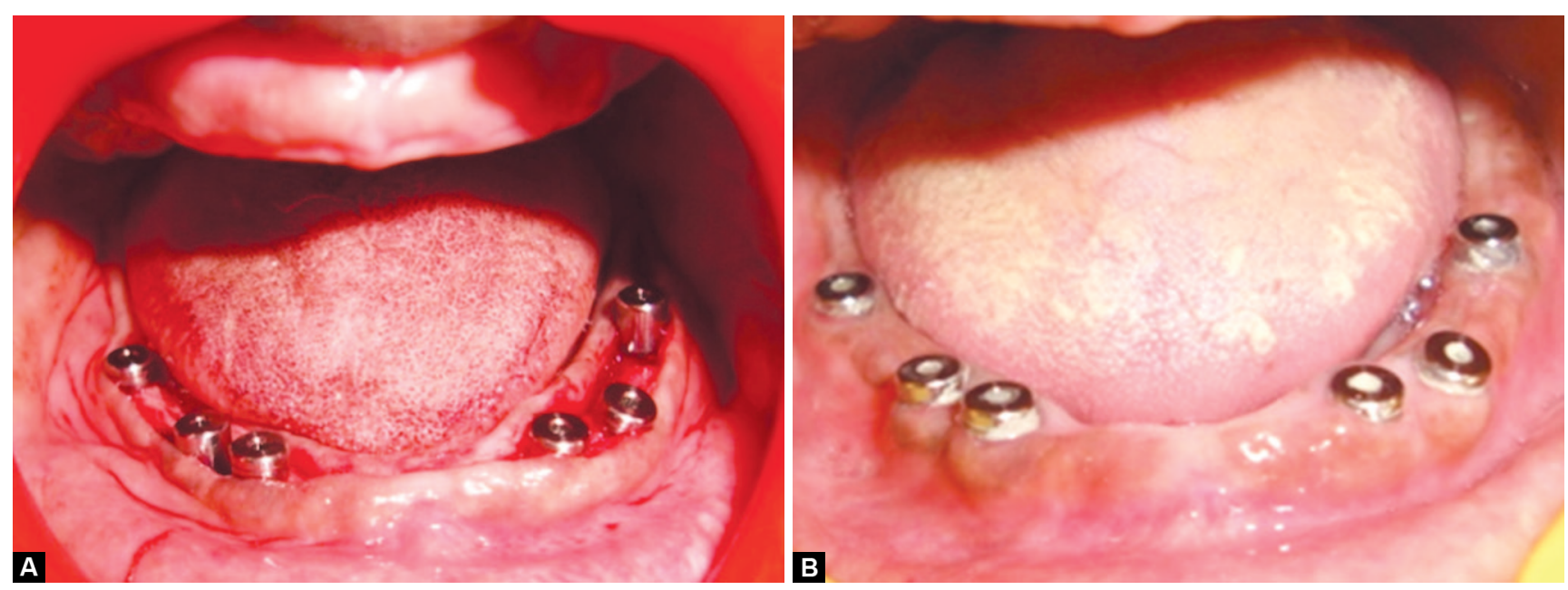

Figs 5A and B: (A) Cover screw exposed and healing abutments in place, (B) one week after healing abutments in place

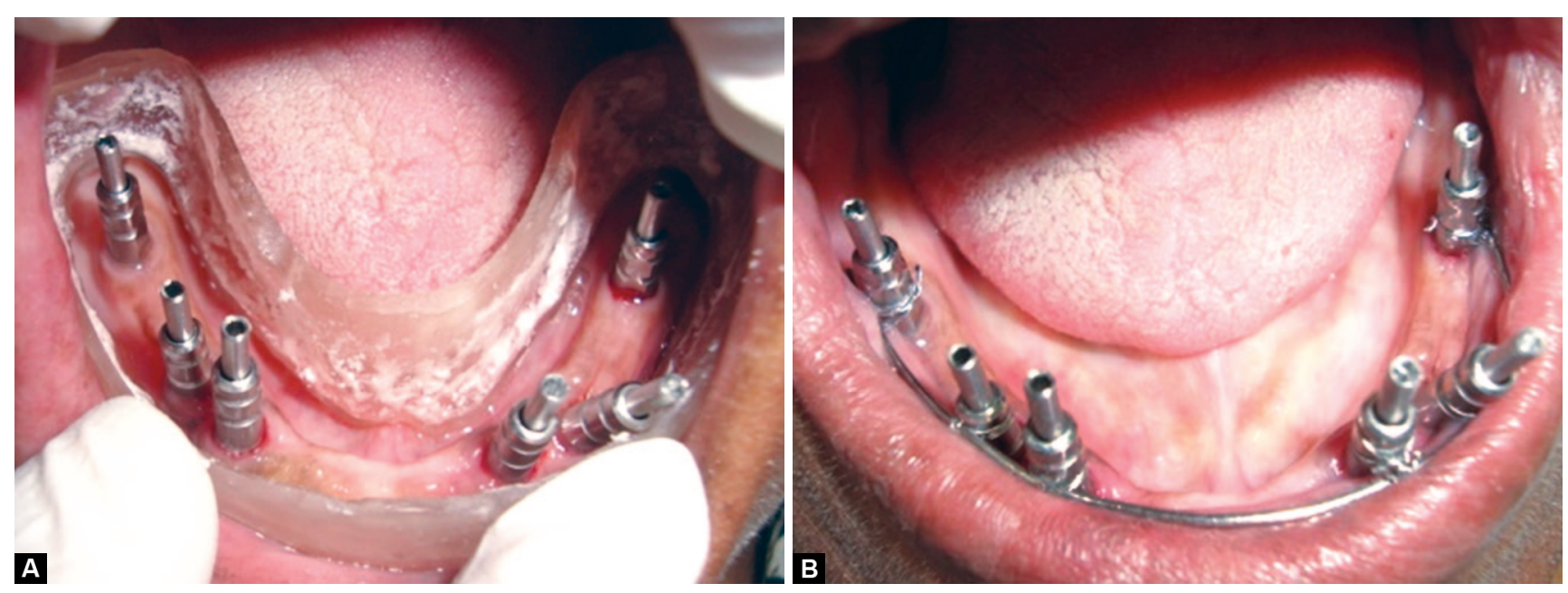

Figs 6A and B: (A) Adjustment and verification of open tray in patient mouth, (B) stabilization of impression copings in patient mouth
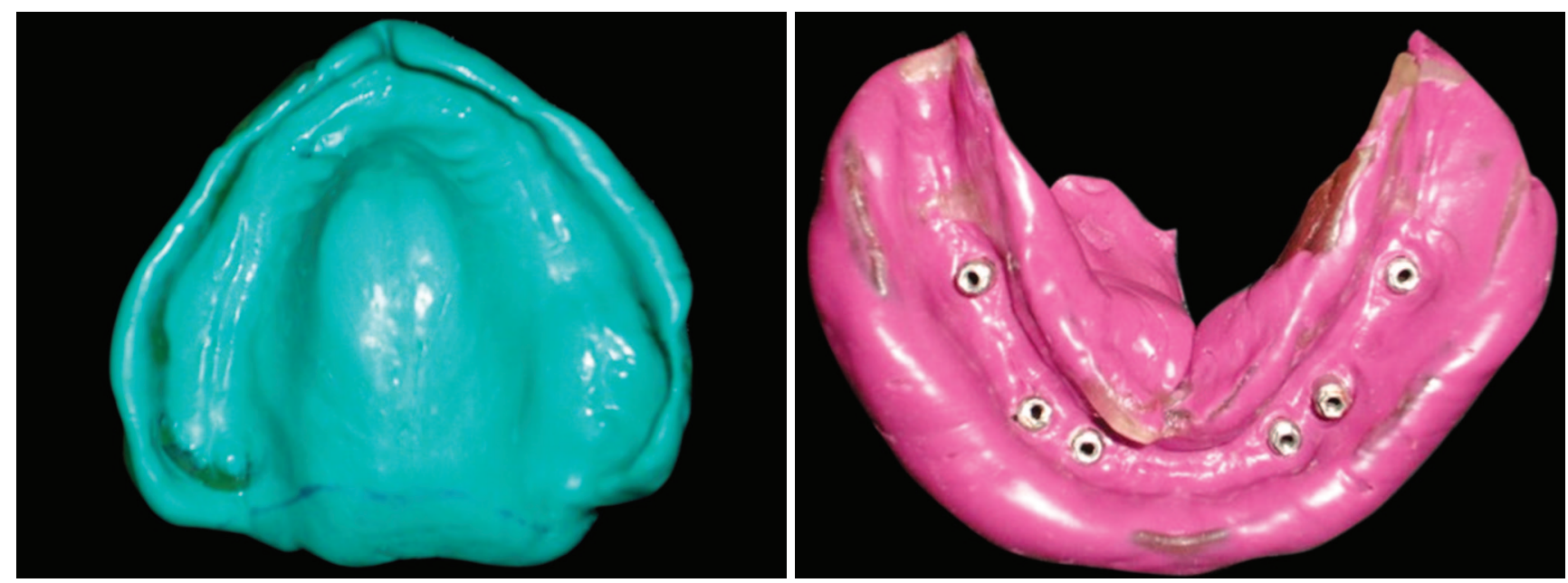

Fig. 7: Maxillary and mandibular final impressions

The casts were poured in die stone (Ultra rock, Kalabhai Karson Pvt Ltd, Mumbai, India) (Fig. 8). The abutments were evaluated in the cast for parallelism (Fig. 9A). It was found that one of the six abutments required an angulation of $15^{\circ}$ for parallelism. Abutments were tried and prepared in the patients mouth and the jaw relation was recorded (Fig. 9B). The abutments were further milled in the lab to attain parallelism and a shoulder finish line. A mock wax-up was done using which a metal framework was fabricated for the Adoro-metal prosthesis (Fig. 10A). The prosthesis was fabricated in three parts: right posterior three unit, left posterior three unit and anterior 

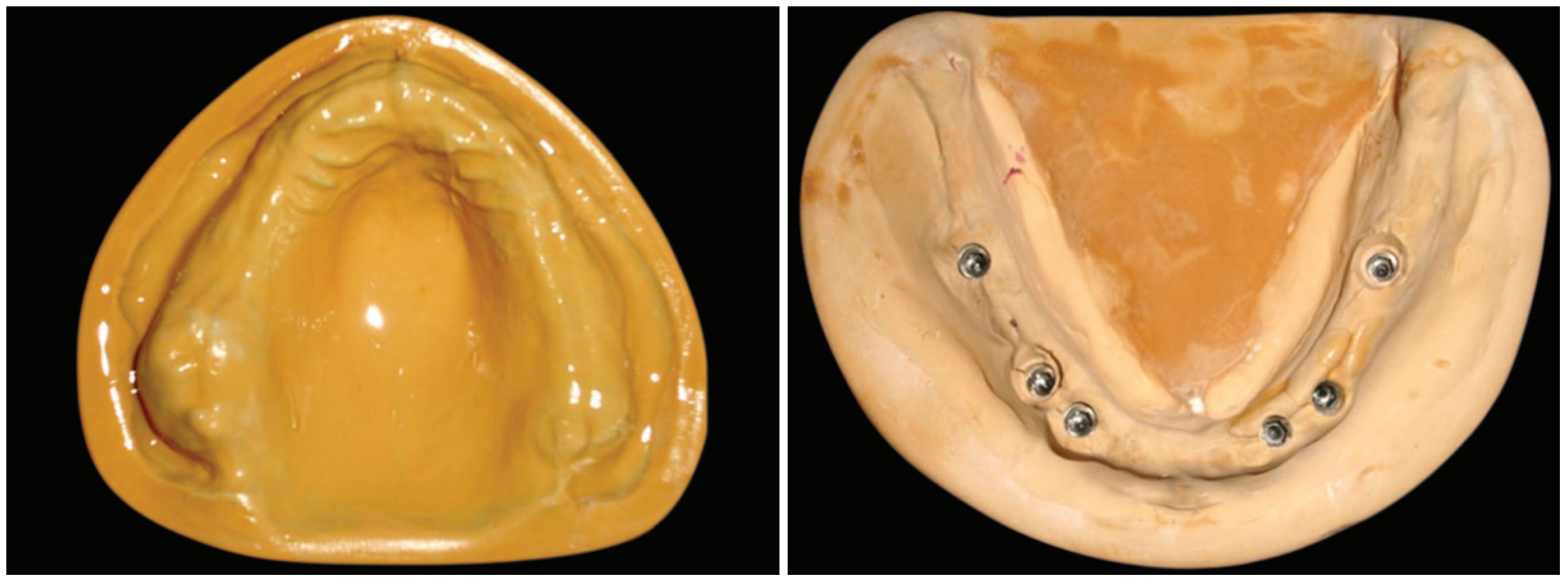

Fig. 8: Maxillary and mandibular master casts
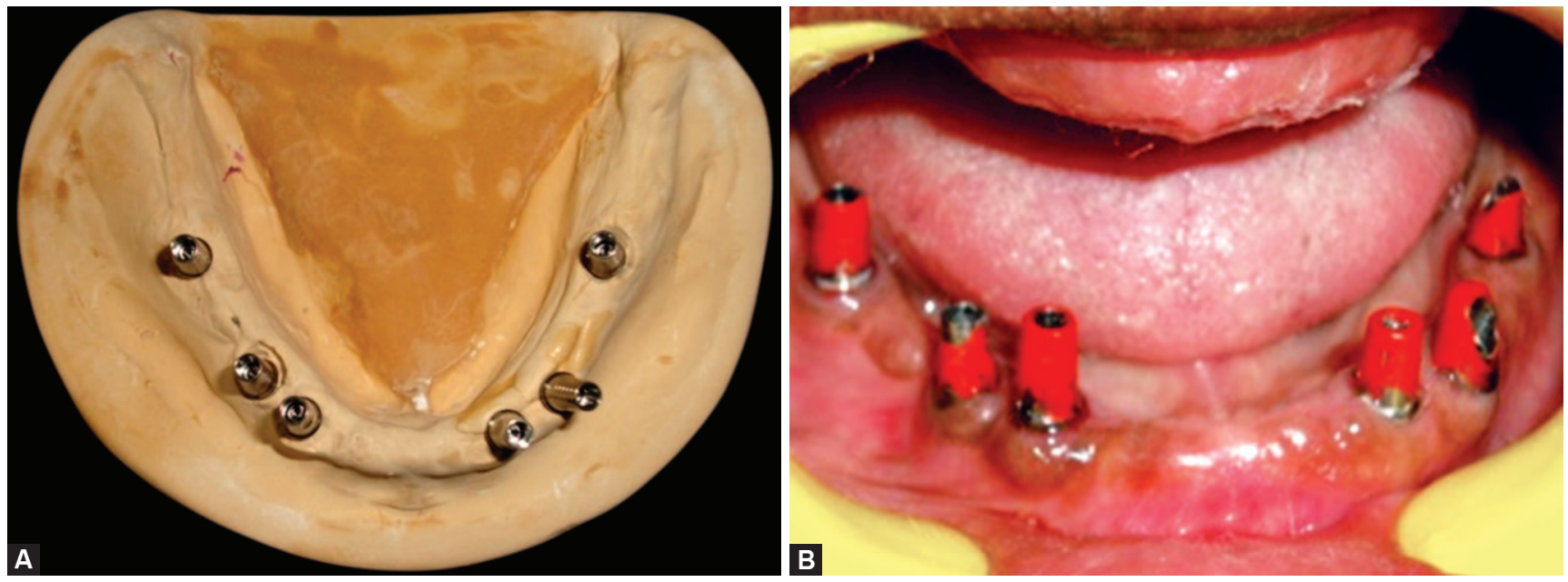

Figs 9A and B: (A) Occlusal view of implant abutments for parallelism, (B) abutment placement and modification intraorally
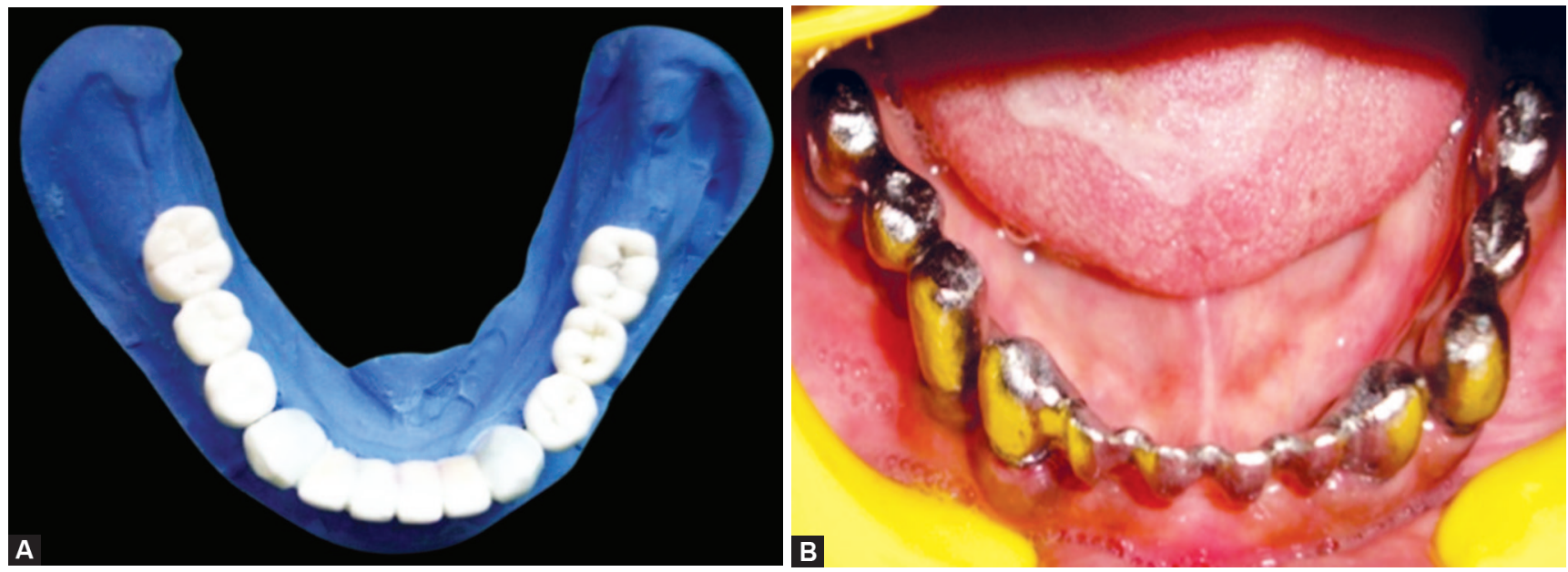

Figs 10A and B: (A) Mock wax-up, (B) metal try in intraorally

six unit fixed dental prostheses. The metal framework was evaluated in the patient's mouth (Fig. 10B) and a new centric record was obtained using an interocclusal registration material (Aluwax, Aluwax Dental Products Co., Grand Rapids, MI, USA). Composite buildup (SR Adoro metal supported, Ivoclar Vivadent AG, Bendererst, Principality of Liechtenstein) of the framework was completed. The prosthesis was cemented (Fuji, Type I, GC, Japan) on the abutments after evaluation. Occlusion was verified with an articulating paper (Ardent Horseshoe style, Whip mix 


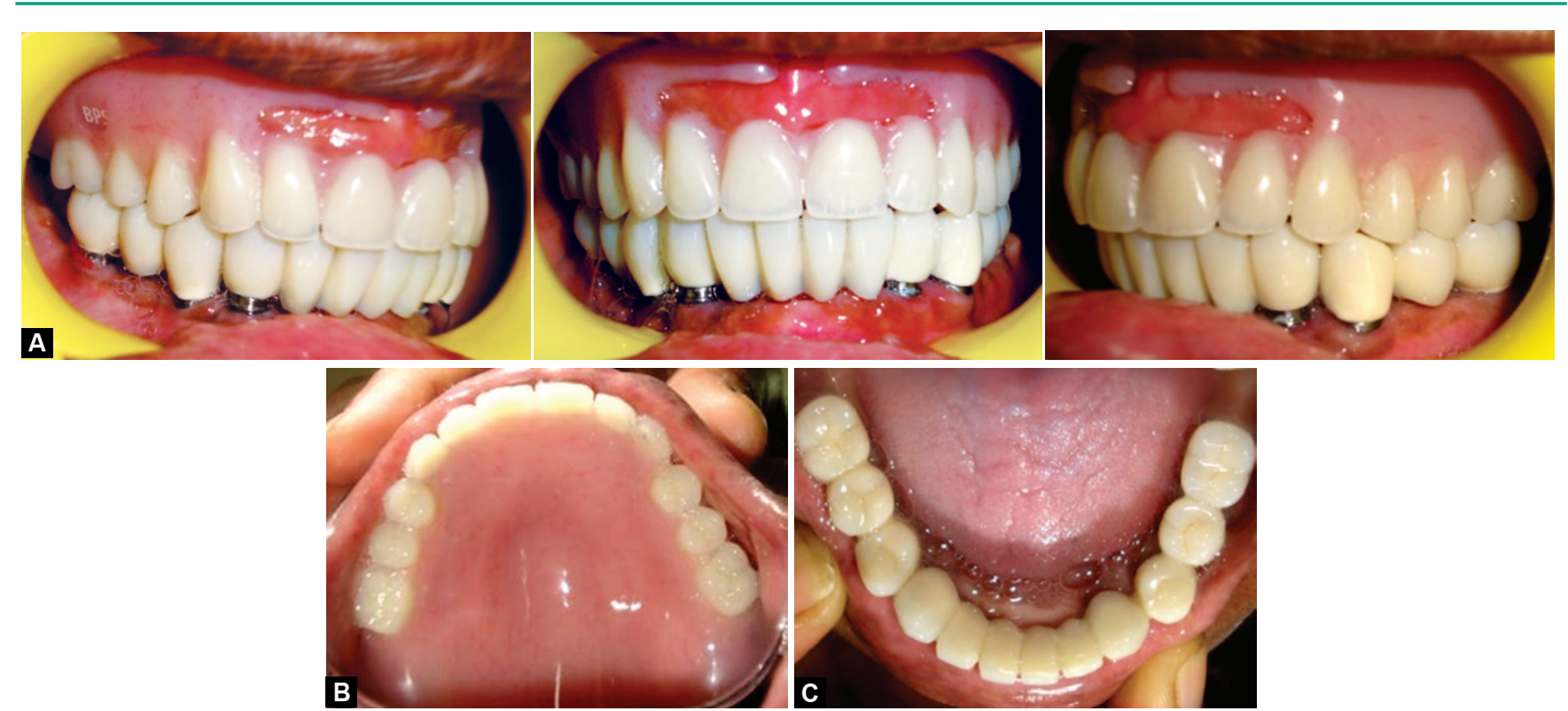

Figs 11A to C: (A) Maxillary and mandibular prosthesis in place, (B) maxillary occlusal view, (C) mandibular occlusal view

Corp., Louisville, Kentucky, USA) which had a thickness of $63 \mu \mathrm{m}$ to ensure balance during lateral movements. The patient was pleased with the esthetic and functional outcome of the dentures (Figs $11 \mathrm{~A}$ to $\mathrm{C}$ ). The patient was advised on postinsertion care and oral hygiene maintenance. The patient was recalled for review every 6 months. The following criteria was used to record details of occlusion, articulation, retention and stability at each visit.

\section{Occlusion and Articulation}

Occlusion was evaluated using guided closure and was considered as: good, if centric relation (CR) coincided with centric occlusion (CO); moderate, if minor $(<0.5 \mathrm{~mm})$ deviation was observed between $\mathrm{CR}$ and $\mathrm{CO}$; poor, if clear $(>0.5 \mathrm{~mm})$ deviation was observed between $\mathrm{CR}$ and CO. Articulation was considered as good when it was fully balanced during lateral movements performed from $\mathrm{CO}$, otherwise it was considered poor. Presence or absence of frontal contact in $\mathrm{CO}$ was also noted. ${ }^{5}$

\section{Retention and Stability}

Retention of the maxillary complete denture was examined using the following scores: (1) good = good resistance to vertical pull, and sufficient resistance to lateral forces;
(2) satisfactory $=$ slight to moderate resistance to vertical pull, and little or no resistance to lateral forces; and (3) poor $=$ no resistance to vertical pull and lateral forces; the denture falls out of place. Stability was determined with the following criteria: (1) good = slight or no rocking on denturesupporting structures when under pressure; (2) moderate = moderate rocking on supporting structures under pressure; and (3) poor $=$ extreme rocking on supporting structures under pressure. ${ }^{5}$

\section{RESULTS}

The results of our study regarding the above mentioned criteria have been presented in Table 1 .

\section{DISCUSSION}

Implants have become an integral part of prosthodontics rehabilitation. Their versatility allows their use in both removable and fixed prostheses. When placement of sufficient number of implants is feasible, the superstructure can be totally implant retained. Careful intraoral examination is crucial to estimate the available inter-arch distance and fabricate the final prosthesis with the necessary strength, esthetics and cleansability. ${ }^{6}$

\begin{tabular}{lllll}
\multicolumn{5}{l}{ Table 1: Clinical findings related to the function of maxillary complete dentures in the 2-year follow-up } \\
\hline Visits & Occlusion & Articulation & Retention & Stability \\
\hline Baseline & Good & Good & Good & Good \\
6 months & Good & Good & Good & Good \\
12 months & Good & Good & Good & Good \\
18 months & Good & Good & Good & Good \\
24 months & Good & Good & Moderate & Moderate \\
\hline
\end{tabular}


Implant retained fixed prostheses have been shown to improve the quality of life for edentulous patients and to contribute to the well-being of the patient's psychology. They offer better satisfaction than conventional dentures. The implant-retained full fixed prosthesis offers several advantages including less food entrapment, less maintenance, longevity and similar overhead cost as completely implant supported overdenture. ${ }^{7,8}$

On semiannual evaluation, occlusion and articulation were found to be good over a period of 2 years. Retention and stability were found to be good uptill the 18 months review. At the 24 months review, there was slight to moderate resistance to vertical pull, little or no resistance to lateral forces and moderate rocking on supporting structures under pressure.

The rehabilitation of edentulous patients with full fixed prosthesis has been observed to achieve greater masticatory function and psychologic satisfaction than with conventional dentures. Occlusal forces have been found to have increased considerably following the placement of an implant retained prosthesis. Residual ridge width of an edentulous maxilla decreases gradually in incisor and canine areas. However, the decrease in maxillary residual ridge width is small and not associated with the type of mandibular restoration. ${ }^{9}$

\section{CLINICAL SIGNIFICANCE}

To preserve anterior maxillary bone, a balanced occlusal concept has been recommended for implant-retained mandibular prostheses opposing a tissue supported conventional maxillary complete denture. ${ }^{10}$ In this case, the patient was rehabilitated with a balanced occlusion without anterior tooth contact in maximal intercuspation. If anterior contact was noticed during the annual recall examination, the occlusion was adjusted to relieve the pressure from the anterior maxilla.

\section{CONCLUSION}

Every patient has unique treatment needs. Proper diagnosis and treatment plan are important but cannot be all-inclusive. A comprehensive examination, including a thorough medical and dental history, orofacial and dental clinical examination, dental radiographs, impressions, and jaw relation records for mounting casts are important steps leading to a successful oral rehabilitation. Careful integration and sequencing of the different areas of treatment needed, enhances the final result. Dentists must consider the advantages and disadvantages the available implant prosthetic options and match them to the patient's expectations. This article reports on the fabrication of a maxillary conventional complete denture opposing a mandibular implant-retained full fixed prosthesis. Occlusion and articulation were found to be good over a period of two years. Retention and stability were found to be good uptill the 18 months review and moderate at the 24 months review.

\section{REFERENCES}

1. Henry PJ. A review of guidelines for implant rehabilitation of the edentulous maxilla. J Prosthet Dent 2002;87:281-288.

2. Kelly E. Changes caused by a mandibular removable partial denture opposing a maxillary complete denture. J Prosthet Dent 1972;27:140-150.

3. Barber HD, Scott RF, Maxson BB, Fonseca RJ. Evaluation of anterior maxillary alveolar ridge resorption when opposed by the transmandibular implant. J Oral Maxillofac Surg 1990;48: 1283-1287.

4. Lechner SK, Mammen A. Combination syndrome in relation to osseointegrated implant-supported over dentures: a survey. Int J Prosthodont 1996;9:58-64.

5. Nevalainen MJ, Rantanen T, Närhi T, Ainamo A. Complete dentures in the prosthetic rehabilitation of the elderly persons: five different criteria to evaluate the need for replacement. J Oral Rehabil 1997;24:251-258.

6. Kleis WK, Kämmerer PW, Hartmann S, Al-Nawas B, Wagner W. A comparison of three different attachment systems for mandibular two-implant overdentures: one-year report. Clin Implant Dent Relat Res 2010;12:209-218.

7. Mericske-Stern R. Treatment outcomes with implant-supported overdentures: clinical considerations. J Prosthet Dent 1998;79: 66-73.

8. Kent G, Johns R. Effects of osseointegrated implants on psychological and social well-being: a comparison with replacement removable prostheses. Int J Oral Maxillofac Implants 1994;9:103-106.

9. Stafford D, Glantz PO, Lindqvist L, Strandman E. Influence of treatment with osseointegrated mandibular bridges on the clinical deformation of maxillary complete dentures. Swed Dent J Suppl 1985;28:117-135.

10. Lang R, Razzoog ME. Lingualized integration: tooth molds and an occlusal scheme for edentulous implant patients. Implant Dent 1992; 1:204-211.

\section{ABOUT THE AUTHORS}

\section{Ashish R Jain (Corresponding Author)}

Senior Lecturer, Department of Prosthodontics, Tagore Dental College and Hospital, Chennai, Tamil Nadu, India, e-mail:dr.ashishjain_r@yahoo.com

\section{Padma Ariga}

Professor and Head, Department of Prosthodontics, Saveetha Dental College, Chennai, Tamil Nadu, India 